\title{
Imported Hyalomma ticks in the Netherlands 2018-2020
}

Mathilde Uiterwijk ${ }^{1 *+}$, Adolfo Ibáñez-Justicia ${ }^{1 \dagger}$, Bart van de Vossenberg ${ }^{2}$, Frans Jacobs ${ }^{1}$, Paul Overgaauw ${ }^{3}$, Rolf Nijsse ${ }^{4}$, Charlotte Dabekaussen ${ }^{3}$, Arjan Stroo ${ }^{1}$ and Hein Sprong ${ }^{5}$

\begin{abstract}
Background: Ticks of the genus Hyalomma, which are vectors for several tick-borne diseases, are occasionally found in areas outside their endemic range including northern parts of Europe. The objective of this study was to analyse adult Hyalomma ticks that were recently found in the Netherlands.

Methods: Hyalomma ticks were morphologically identified. Cluster analysis, based upon sequence data (cox1 barcoding) for molecular identification, and pathogen detection were performed. Additionally, a cross-sectional survey of horses was conducted to actively search for Hyalomma ticks in summer 2019. Analysis of temperature was done to assess the possibility of (i) introduced engorged nymphs moulting to adults and (ii) establishment of populations in the Netherlands.

Results: Seventeen adult Hyalomma ticks (one in 2018, eleven in 2019, five in 2020) were found by citizens and reported. Fifteen ticks were detected on horses and two on humans. Twelve were identified as H. marginatum, one as H. rufipes and four, of which only photographic images were available, as Hyalomma sp. No Crimean-Congo haemorrhagic fever virus or Babesia/Theileria parasites were detected. One adult tick tested positive for Rickettsia aeschlimannii. In the cross-sectional horse survey, no Hyalomma ticks were found. Analysis of temperatures showed that engorged nymphs arriving on migratory birds in spring were able to moult to adults in 2019 and 2020, and that cumulative daily temperatures in the Netherlands were lower than in areas with established H. marginatum populations.

Conclusions: Our results show that Hyalomma ticks are regularly introduced in the Netherlands as nymphs. Under the Dutch weather conditions, these nymphs are able to develop to the adult stage, which can be sighted by vigilant citizens. Only one human pathogen, Rickettsia aeschlimannii, was found in one of the ticks. The risk of introduction of tick-borne diseases via Hyalomma ticks on migratory birds is considered to be low. Establishment of permanent Hyalomma populations is considered unlikely under the current Dutch climatic conditions.
\end{abstract}

Keywords: Surveillance, Vector-borne disease, One Health, Viral haemorrhagic fever, Cluster analysis, Citizen science

${ }^{*}$ Correspondence: m.uiterwijk@nvwa.nl

${ }^{\dagger}$ Mathilde Uiterwijk and Adolfo Ibáñez-Justicia contributed equally to this work

${ }^{1}$ Centre for Monitoring of Vectors (CMV), National Reference Laboratory, Netherlands Food and Consumer Product Safety Authority (NVWA), Wageningen, the Netherlands

Full list of author information is available at the end of the article

\section{Background}

Ticks of the genus Hyalomma (Acari: Ixodidae) are endemic in semi-arid regions across Asia, Africa and Europe [1-3]. Incidentally, specimens of Hyalomma marginatum sensu lato (Koch, 1844) have been reported far from the boundaries of their endemic range [4]. Migrating birds play an important role in long-distance dispersal of immature stages of $H$. marginatum s.l. into new areas. In studies performed in southern and eastern parts

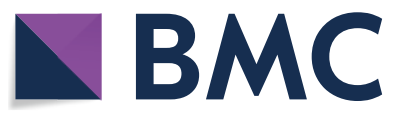

(c) The Author(s) 2021. This article is licensed under a Creative Commons Attribution 4.0 International License, which permits use, sharing, adaptation, distribution and reproduction in any medium or format, as long as you give appropriate credit to the original author(s) and the source, provide a link to the Creative Commons licence, and indicate if changes were made. The images or other third party material in this article are included in the article's Creative Commons licence, unless indicated otherwise in a credit line to the material. If material is not included in the article's Creative Commons licence and your intended use is not permitted by statutory regulation or exceeds the permitted use, you will need to obtain permission directly from the copyright holder. To view a copy of this licence, visit http://creativeco mmons.org/licenses/by/4.0/. The Creative Commons Public Domain Dedication waiver (http://creativecommons.org/publicdomain/ zero/1.0/) applies to the data made available in this article, unless otherwise stated in a credit line to the data. 
of Europe for which thousands of migratory birds were checked for ticks, several hundreds of larvae and nymphs of Hyalomma spp. were collected [5-14]. In northern and western parts of Europe such as in the United Kingdom [11], Sweden [12], Norway [13] and the Netherlands [15], immature stages of Hyalomma spp. were also found on migrating birds, but to a lesser extent. Occasionally, adults of $H$. marginatum have been found in northern and western European countries [16-23]. In the Netherlands, three adult Hyalomma sp. ticks were reported on horses between 2005 and 2009 [24, 25], and one adult Hyalomma sp. tick was found attached to a person in 2012 [26].

Hyalomma marginatum is a species complex including $H$. marginatum, $H$. turanicum and H. rufipes [27]. Hyalomma marginatum are two-host ticks. The larvae and nymphs feed on small mammals, ground-dwelling birds and reptiles [28]. Larval feeding, moulting to nymphal stage and nymphal feeding will in most cases occur on the same host, on which the immature stages can be present for up to 26 days [29, 30]. Adult Hyalomma ticks feed on ungulates such as Bovidae, Equidae, Cervidae and Suidae, but also (smaller) mammals such as Canidae, Lagomorpha and occasionally humans [28, 31].

H. marginatum ticks can transmit tick-borne pathogens such as Crimean-Congo haemorrhagic fever virus (CCHFv) and spotted fever rickettsiae to humans, Babesia caballi and Theileria equi (piroplasmosis) to horses, and T. annulata (tropical theileriosis) to bovines. Therefore, this tick species is of public and veterinary health concern [28, 32-34].

In this study we describe citizen reports of adult Hyalomma ticks in the Netherlands, and the results of a survey that was undertaken to actively search for Hyalomma ticks after the first sightings in 2019. The results of the molecular identification and the pathogen analysis of the specimens are discussed. Furthermore, we evaluate the possibility of nymph moulting, wintering and establishment of Hyalomma ticks after introduction in the Netherlands, based upon climatic data.

\section{Methods}

\section{Tick collection}

\section{Citizens' notification}

From the beginning of summer 2019, and after receiving the first notification of Hyalomma, citizens were engaged to report Hyalomma ticks by posting information on the websites of the Netherlands Food and Consumer Product Safety Authority (NVWA) (www.nvwa.nl/reuzenteek) and the National Institute for Public Health and the Environment (RIVM) (www.rivm.nl/tekenbeten-en-lyme/ hyalomma-teken). Citizens could send photographic images of Hyalomma ticks to the Centre for Monitoring of Vectors (CMV, NVWA, National Reference Centre, the Netherlands) via email or using the specific $\mathrm{Hya}$ lomma tick report system included on the NVWA website. After evaluation of the photographic images by entomologists, suspected Hyalomma specimens were transported to the laboratory and the contributors were questioned for additional information by telephone or on-site. When on-site, relevant animals present and vegetation nearby were carefully inspected for other possible Hyalomma ticks.

\section{Cross-sectional horse study}

After receiving the first notification of Hyalomma, a cross-sectional study was performed to investigate the presence of Hyalomma ticks on horses. For this, 40 horse farms and equestrian centres, located in rural wooded areas in the northern and eastern part of the Netherlands, were visited between August and October 2019 (Fig. 1). Locations were visited once, and at each location five horses were carefully examined for ticks, in particular the nose, neck, chest, under the manes and tail, between the legs and the legs themselves. Horses were selected based upon having outdoor activities on a regular basis and/or being grazed and/or frequently being infested with ticks in the past.

\section{Tick identification \\ Morphological identification}

Ticks that arrived in the laboratory (Table 1) were morphologically identified by tick specialists according to the keys of Estrada-Peña et al. and Walker et al. [35, 36]. After morphological identification, the ticks were immediately processed for molecular and pathogen detection or first individually stored at $-80{ }^{\circ} \mathrm{C}$ before further analysis.

\section{Molecular identification and cluster analysis}

Molecular identification was performed by Sanger sequencing of the partial mitochondrial $\operatorname{cox} 1$ gene using primers LCO1490 and HCO2198 [37] according to the European and Mediterranean Plant Protection Organization (EPPO) DNA barcoding standard PM7/129(1) [38]. In short, a few legs of the specimen were used as input for the DNA extraction. Tick tissue was ground in a lysis buffer with a micro-pestle prior to DNA extraction with the High Pure ${ }^{\circledR}$ polymerase chain reaction (PCR) template preparation kit (Roche, Basel, Switzerland). Positive and negative controls were always included to detect possible contamination and to monitor the efficiency of Sanger sequencing and assembly. Amplicons were purified with the QIAquick ${ }^{\circledR}$ PCR Purification Kit (Qiagen, Venlo, the Netherlands) prior to cycle sequencing with both amplification primers in individual runs using the 


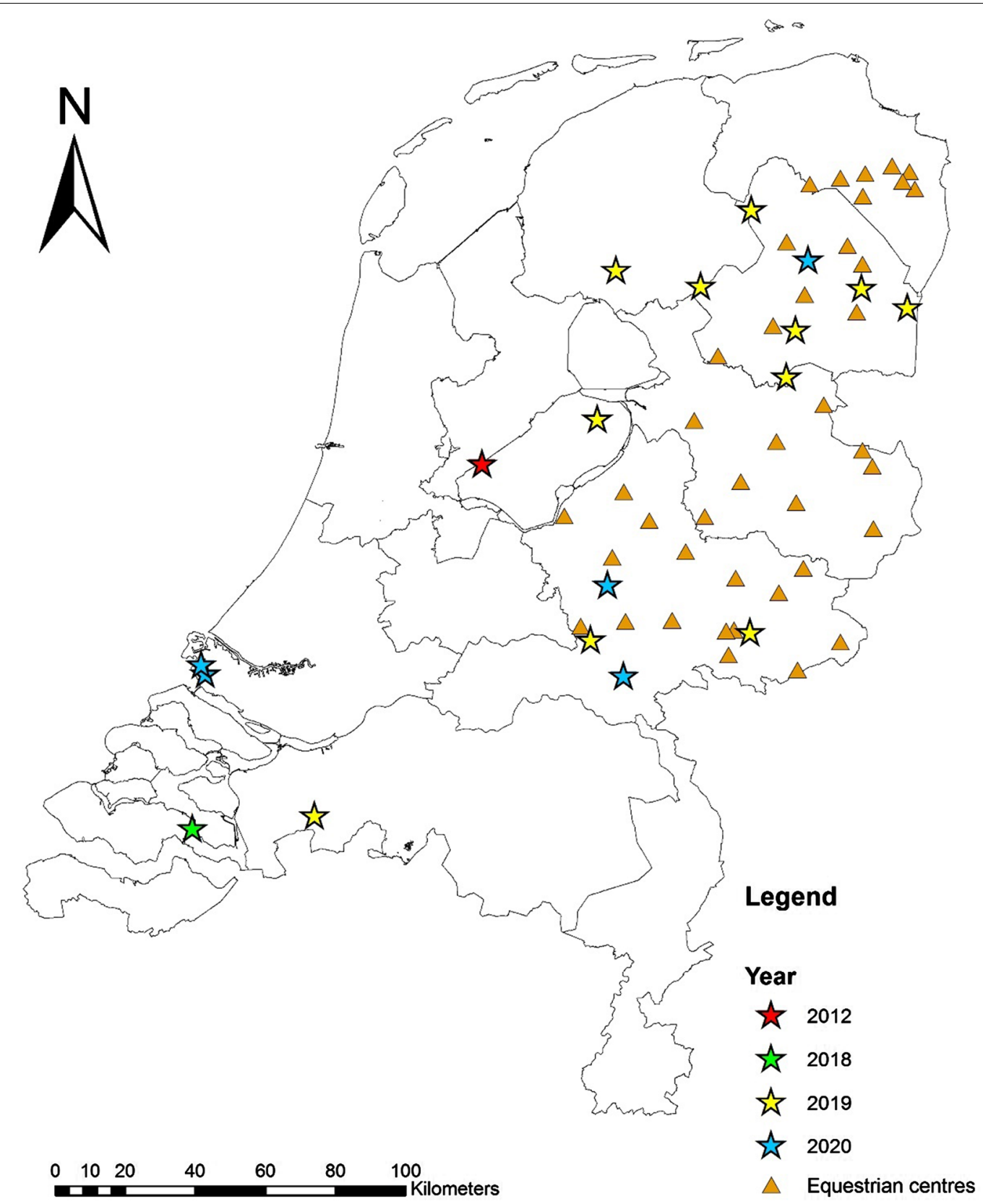

Fig. 1 Location of Hyalomma ticks found in the Netherlands (stars), and equestrian centres visited for the horse survey in 2019 (triangles)

BigDye $^{\circledR}$ Terminator v1.1 Cycle Sequencing Kit (Life Technologies, Carlsbad, CA). Cycle sequence products were purified with DyeEx ${ }^{\circledR} 2.0$ Spin Kit columns (Qiagen, Venlo, the Netherlands) prior to sequencing on a 3500 Genetic Analyzer (Life Technologies, Carlsbad, CA).

Electropherograms were assembled in Geneious Prime 2019.2.3 (Biomatters, Auckland, New Zealand), and consensus sequences were aligned with selected
NCBI accessions using MAFFT [39]. After masking $5^{\prime}$ and $3^{\prime}$ overhang sequences in the 896-base-pair (bp) alignment, 542 bp were represented by all specimens in the alignment which were included in the clustering analysis. The alignment was subjected to a UPGMA (unweighted pair group method with arithmetic mean) clustering analysis using the tree builder tool incorporated in Geneious Prime (HKY85 substitution model; 100 bootstraps). 
Hyalomma sequences generated in this study were deposited in the NCBI GenBank ${ }^{\circledR}$ database under the accession numbers MT757612 to MT757622, and MW495246 to MW495248.

\section{Pathogen detection DNA and RNA extraction}

For pathogen detection, the remaining tick bodies were lysed and homogenized in RNAlater ${ }^{\circledR}$ (Thermo Fisher Scientific, Leiden, the Netherlands), and subsequently processed according to the manufacturer's instructions in a diagnostic laboratory setting (Nucleic Acid Isolation Kit I; Roche). Extraction of whole nucleic acid from the ticks was performed using robot extraction (MagNA Pure Compact Extraction Robot; Roche, Basel, Switzerland). To detect potential cross-contamination, negative controls were included in each extraction batch. Samples were analysed with different (real-time) PCRs based on various genes specific for the microorganism of interest and carried out on a LightCycler $^{\circledR} 480$ (Roche Diagnostics Nederland B.V., Almere, the Netherlands). Positive (plasmid) controls and negative water controls were used on every plate tested. To minimize contamination leading to falsepositive samples, the DNA/RNA extraction, PCR mix preparation, sample addition and (q)PCR analyses were performed in separated air-locked dedicated labs.

\section{Crimean-Congo haemorrhagic fever virus}

For detection of CCHFv, a reverse transcription realtime PCR was performed [40].

\section{Babesia and Theileria}

Primers recognizing a 400-440-bp fragment of the $18 \mathrm{~S}$ rRNA gene of both Babesia spp. and the closely related Theileria spp. were used for PCR amplification [41].

\section{Rickettsiae}

Lastly, for the detection and identification of spotted fever rickettsiae, real-time PCR was performed on the citrate synthase $(g l t A)$ gene [42]. On positive samples, the partial outer membrane protein $\operatorname{omp} B$ gene was amplified with conventional PCR and used for sequencing [43]. The Rickettsia sequence generated in this study was deposited in the NCBI GenBank ${ }^{\circledR}$ database under accession number MW498244.

\section{Evaluation of Hyalomma tick moulting and wintering after introduction}

We assume that the Hyalomma ticks found in the Netherlands were introduced on migratory birds in early spring. These ticks were introduced as feeding nymphs, and after processing the blood meal they completed the moult to the adult stage in the environment. This last step is a temperature-dependent process. We evaluated the possibility of engorged nymphs successfully moulting to adults using two different criteria: (i) about $300{ }^{\circ} \mathrm{C}$ cumulative degrees above the developmental zero $\left(14-16{ }^{\circ} \mathrm{C}\right)$ is necessary to complete the moult [44], and (ii) temperatures of $>8{ }^{\circ} \mathrm{C}$ for 15 continuous days ensure the moulting of nymphs [45].

We also evaluated the possibility of Hyalomma wintering and establishment using the temperature-related limiting factor described by Gray et al. (2009), where temperatures between September and December are critical for wintering of $H$. marginatum ticks. As suggested by these authors, and using a threshold of $10{ }^{\circ} \mathrm{C}$, we considered that areas with average cumulative temperatures of $800{ }^{\circ} \mathrm{C}$ between September and December would be suitable and areas below $400{ }^{\circ} \mathrm{C}$ would be unsuitable for the species [46].

Daily average temperature values were obtained from available data of the Royal Netherlands Meteorological Institute (KNMI). For the calculations, we downloaded the data for the weather stations "De Bilt" (situated centrally in the Netherlands) and "Heino" and "Hoogeveen" situated in the vicinity of most of the Hyalomma sighting locations (Fig. 1).

\section{Results}

Tick specimens

\section{Citizens' notifications}

From July 2019 to December 2020, 118 sightings of 'Hyalomma ticks' were reported (Additional file 1: Table S1). Also, one adult Hyalomma sp. tick had been found in 2018 but was reported in 2020. Of these, 17 specimens (one in 2018, 11 in 2019, five in 2020, see Table 1) could be classified as adult Hyalomma sp. ticks based upon photographic images provided by the citizens. Figure 1 shows the locations were the ticks were found.

The 102 reports which were not Hyalomma ticks were identified as other tick species $(n=51)$, mostly of the genera Ixodes sp. and Dermacentor sp., but also hemipterans $(n=15)$, spiders $(n=10)$, louse flies $(n=6)$, other arthropods or unidentifiable.

Of all reported adult Hyalomma ticks, nearly all (15/17) were discovered on horses. Two ticks were discovered on humans, both not attached. The horses on which the ticks were found were all kept (partly) on pasture, and most horses were taken for outdoor rides on a regular basis. None of the horses or persons on which the adult ticks were found had (recently) been abroad. We enquired where the ticks were most likely acquired, and whether similar ticks were observed recently or earlier. In about half of the reports, we checked on-site whether other 


\begin{tabular}{|c|c|c|c|c|c|c|c|c|c|c|c|}
\hline Date found & $\begin{array}{l}\text { Municipality } \\
\text { name }\end{array}$ & Province & Found on & Stage & $M / F$ & $\begin{array}{l}\text { Morphological } \\
\text { identification }\end{array}$ & Cluster analysis & Genbank acc. no. & CCHFV & Rickettsia & Theileria/Babesia \\
\hline 5 June 2012 & Almere & Flevoland & Bird & Nymph & hn.a. & Hyalomma sp. & H. rufipes & MT757612 & - & - & - \\
\hline $\begin{array}{l}18 \text { Septem- } \\
\text { ber } 2018\end{array}$ & Yerseke & Zeeland & Horse & Adult & M & Hyalomma sp.* & $x$ & $x$ & $x$ & $x$ & $x$ \\
\hline 4 July 2019 & Zelhem & Gelderland & Horse & Adult & $\mathrm{F}$ & Hyalomma sp.* & $x$ & $x$ & $x$ & $x$ & $x$ \\
\hline 14 July 2019 & Odoorn & Drenthe & Horse & Adult & $\mathrm{F}$ & H. marginatum & H. marginatum & MT757622 & - & + & - \\
\hline 30 July 2019 & Dronten & Flevoland & Horse & Adult & $\mathrm{F}$ & H. marginatum & H. marginatum & MT757619 & - & - & - \\
\hline $\begin{array}{l}6 \text { August } \\
2019\end{array}$ & Oldeouwer & Friesland & Human & Adult & M & Hyalomma sp.* & $x$ & $\mathrm{x}$ & $x$ & $x$ & $x$ \\
\hline $\begin{array}{l}7 \text { August } \\
2019\end{array}$ & $\begin{array}{l}\text { Emmer-Com- } \\
\text { pascuum }\end{array}$ & Drenthe & Horse & Adult & M & Hyalomma sp. & H. marginatum & MT757618 & - & - & - \\
\hline $\begin{array}{l}14 \text { August } \\
2019\end{array}$ & Linde & Drenthe & Horse & Adult & $\mathrm{F}$ & H. marginatum & H. marginatum & MT757613 & - & - & - \\
\hline $\begin{array}{l}14 \text { August } \\
2019\end{array}$ & Eén & Drenthe & Horse & Adult & $\mathrm{F}$ & H. marginatum & H. marginatum & MT757621 & - & - & - \\
\hline $\begin{array}{l}20 \text { August } \\
2019\end{array}$ & Tiendeveen & Drenthe & Horse & Adult & M & H. marginatum & H. marginatum & MT757616 & - & - & - \\
\hline $\begin{array}{l}23 \text { August } \\
2019\end{array}$ & Noordwolde & Friesland & Horse & Adult & $\mathrm{F}$ & H. marginatum & H. marginatum & MT757615 & - & - & - \\
\hline $\begin{array}{l}27 \text { August } \\
2019\end{array}$ & Rucphen & Noord-Brabant & Human & Adult & M & H. marginatum & H. marginatum & MT757614 & - & - & - \\
\hline $\begin{array}{l}20 \text { Septem- } \\
\text { ber } 2019\end{array}$ & Wageningen & Gelderland & Horse & Adult & $\mathrm{F}$ & H. marginatum & H. marginatum & MT757617 & - & - & - \\
\hline 4 May 2020 & Amen & Drenthe & Horse & Adult & $\mathrm{F}$ & Hyalomma sp. & H. marginatum & MT757620 & - & - & - \\
\hline $\begin{array}{l}4 \text { August } \\
2020\end{array}$ & Oosterhout & Gelderland & Horse & Adult & $\mathrm{F}$ & Hyalomma sp. & H. marginatum & MW495246 & - & - & - \\
\hline $\begin{array}{l}11 \text { August } \\
2020\end{array}$ & Rockanje & Zuid-Holland & Horse & Adult & $\mathrm{F}$ & H. rufipes & H. rufipes & MW495248 & - & - & - \\
\hline $\begin{array}{l}15 \text { August } \\
2020\end{array}$ & Oostvoorne & Zuid-Holland & Horse & Adult & $\mathrm{F}$ & Hyalomma sp. & H. marginatum & MW495247 & - & - & n.t. \\
\hline $\begin{array}{l}\text { 4 September } \\
2020\end{array}$ & r Harskamp & Gelderland & Horse & Adult & \multicolumn{2}{|c|}{ Unknown Hyalomma sp.* } & $x$ & $x$ & $x$ & $x$ & $x$ \\
\hline
\end{tabular}

+ detected, - not detected, ${ }^{*}$ identification based on photographic images, $x$ specimen not available for laboratory analyses

$M$ male, $F$ female, CCHFv Crimean-Congo haemorrhagic fever virus, n.a. not applicable, n.t. not tested

Table 1 Information about Hyalomma ticks and results of laboratory analyses (morphological and molecular identification, and pathogen detection)

specimens were present on animals or in the vegetation. Consequently, no other Hyalomma ticks were reported or detected. On average, it took 1.9 days (range 0-4 days) for a found tick to arrive at the laboratory. Nearly all ticks were dead on arrival at the laboratory.

\section{Morphological and molecular species identification and pathogen detection}

Thirteen of the 17 reported adult Hyalomma ticks and one nymph that was found on a migratory bird (Eurasian reed warbler Acrocephalus scirpaceus) in 2012 were available for further investigation (Table 1).

\section{Morphological species identification}

Morphological analysis in the laboratory identified eight of the adult Hyalomma ticks as $H$. marginatum and one as $H$. rufipes (Table 1 ). Four adult ticks and the nymph could not be morphologically identified to species level with certainty in the laboratory (Table 1).

\section{Molecular species identification and cluster analysis}

A total of 91 partial cox 1 gene sequences were included in the alignment, representing 77 selected sequences deposited in NCBI GenBank ${ }^{\circledR}$ (see Additional file 1: Table S2) and 14 specimens (13 adults and 1 nymph) from the Netherlands generated in this study. Results of the cox 1 sequence molecular analysis (UPGMA; HKY85, 100 bootstraps) showed that the specimens found in our study cluster in two major clades (Fig. 2). The first clade, with $98 \%$ bootstrap support, clusters 12 adult specimens with $H$. marginatum (24), $H$. turanicum (5) and $H$. rufipes (1) NCBI sequences. The second clade, with $100 \%$ 
bootstrap support, clusters one adult specimen and the nymph with $H$. rufipes (9), H. dromedarii (1) and H. truncatum (1) NCBI sequences. As shown in Fig. 2, H. dromedarii and $H$. truncatum sequences are also represented in other clades. According to combined morphological and molecular identification (Table 1), 12 adult ticks can be classified as $H$. marginatum and one as $H$. rufipes. The nymph can be classified as $H$. rufipes.

\section{Pathogen detection}

Results of the pathogen detection analysis (Table 1) show that one adult $H$. marginatum tick reported in 2019 tested positive for Rickettsia sp., more specifically $R$. aeschlimannii. In the other 13 Hyalomma ticks that were tested, no pathogens were detected.

\section{Cross-sectional horse study}

A total of 202 horses from 40 equestrian centres (Fig. 1) were examined for the presence of ticks in 2019. In this survey, no Hyalomma ticks were found during the inspections or reported by the caretakers. Six Ixodes ticks were found on five horses.

\section{Accumulated daily temperature analysis}

Using the parameters obtained in the laboratory by Emelyanova et al. (2005), and using the lowest developmental zero temperature suggested $\left(T_{0}=14{ }^{\circ} \mathrm{C}\right)$, if $\mathrm{Hya}$ lomma nymphs were introduced early in spring in 2019 (1st of April), results show that the first adult would be expected to appear approximately during the first days of August in 2019. This result does not match the first Hyalomma adult sighting in 2019 reported 1 month earlier (on 4th of July).

However, results applying the temperature parameters used in the study by Gale et al. (2012) show that in the spring of 2019 (from 15 April 2019 until 2 May 2019) and 2020 (from 15 April 2020 until 2 May 2020) temperatures of $>8{ }^{\circ} \mathrm{C}$ for 15 or more continuous days were recorded prior to the citizens' sightings of Hyalomma adults, allowing the engorged nymphs to moult to adults.

In 2018 and 2019, cumulative temperatures above $10^{\circ} \mathrm{C}$ between September and December (weather station " Heino") totalled $216^{\circ} \mathrm{C}$ and $192{ }^{\circ} \mathrm{C}$, respectively, indicating that this area is not considered suitable for the establishment of populations of $H$. marginatum (cumulative temperature below $400{ }^{\circ} \mathrm{C}$ ), according to Gray et al. [46].

\section{Discussion}

Ticks of the $H$. marginatum complex are known vectors of diseases of veterinary and public health importance, and are able to survive in a wide range of climatic conditions and a variety of habitats [31]. In this study, we report citizens' notifications of Hyalomma adults in the Netherlands. Results of this study raise questions about the frequency of introductions and the ability to establish endemic Hyalomma populations in the Netherlands which calls for vigilance because of the possible risk to human and animal health.

Even though Hyalomma ticks have been found and reported before in the Netherlands [15, 24-26], the numbers of adult Hyalomma ticks reported within the past few years seem unprecedented. In the weeks preceding the sightings in 2019, the media reported about adult Hyalomma ticks in horse farms in Germany [47] in a sensationalistic way. The sighting of the first Hyalomma ticks in the Netherlands that year boosted the media attention. There, the Hyalomma ticks were described as 'giant,' 'monster' or 'horror' ticks and were connected to 'a deadly Ebola-like virus' (meaning CCHFv), which probably led to an increased awareness among the public. Fifteen out of 17 adult Hyalomma ticks were discovered on horses. This is most likely explained by the fact that horses, in contrast to other hosts for Hyalomma adults, are closely inspected and handled on a regular basis by their caretakers during grooming and saddling.

Of the thirteen available adult Hyalomma ticks (Table 1), eight could be morphologically identified as $H$. marginatum and one as $H$. rufipes. Four could not be morphologically identified to species level with certainty, due to the poor state (dried out and/or moldy) of the specimens received. Also, the engorged nymph that was found on a migratory bird in 2012 [15] could not be morphologically identified to species level, because of the difficulties arising in morphological identification of $\mathrm{Hya}$ lomma nymphs to species level [27, 35].

Molecularly, 12 adults, including the eight ticks that were morphologically identified as $H$. marginatum, clustered mainly with $H$. marginatum (24). Also in this cluster were two other members of the $H$. marginatum species complex, H. turanicum (5) and $H$. rufipes (1) (Fig. 2). The one adult that was morphologically identified as $H$. rufipes and the nymph clustered mainly with $H$. rufipes (9). One $H$. dromedarii and one $H$. truncatum were also in this cluster, which also clustered together in their own cluster (Fig. 2). Ticks from the H. marginatum species complex are known to be taxonomically challenging to identify [27]. Also, cryptic hybridization in Hyalomma ticks might at least partly account for the apparent incongruence between morphology and molecular clustering [48].

$H$. rufipes has also been found in western and northern European countries [13, 18]. To our knowledge, $H$. dromedarii and $H$. truncatum specimens have not been found in western and northern European countries. In our consideration, we also took into account the fact that 


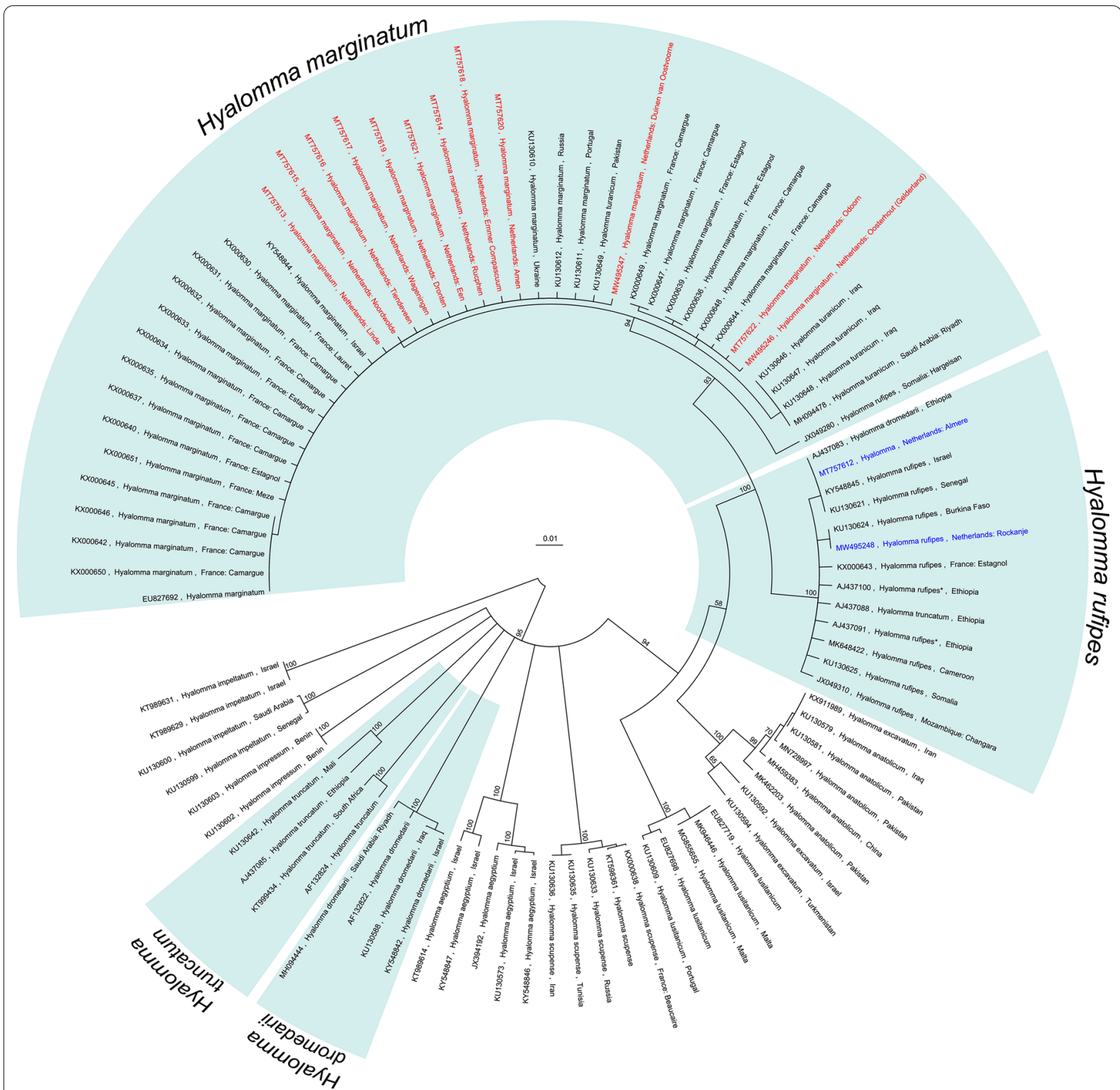

Fig. 2 Cluster analysis of Hyalomma specimens. Cladogram of a fragment of the mitochondrial cox 1 gene based on 77 selected NCBI accessions and 12 Hyalomma specimens found during this study. Organism names of sequences indicated with an asterisk $\left(^{*}\right)$ have been altered relative to the NCBI record based on information provided in the original paper

H. rufipes is a two-host tick of which the immatures are most likely to seek (migratory) birds as hosts, in contrast to $H$. dromedarii and H. truncatum [35, 36]. Combining morphological and molecular identification, we classified the 12 adults as $H$. marginatum, and both the adult and nymph as $H$. rufipes.

The ticks were most likely introduced via migratory birds. In general, migrating birds that breed in the Netherlands and winter in warmer climates can be divided into two groups. Birds belonging to the first group migrate over long distances, and winter in Africa (Sahel to more southern regions). The mass arrival in the Netherlands of these birds, such as garden warbler (Sylvia borin), common whitethroat (S. communis), willow warbler (Phylloscopus trochilus) and common redstart (Phoenicurus phoenicurus), is from mid-April to May. The second group consists of birds that winter much nearer, in southern Europe and northern Africa. These birds, such as the 
European robin (Erithacus rubecula), song thrush (Turdus philomelos), common chiffchaff (Phylloscopus collybita) and Eurasian blackcap (Sylvia atricapilla), arrive from March onwards, leaving the African and Mediterranean European countries already in February. In the wintering and stop-over areas of both groups, Hyalomma ticks are endemic and can be dispersed via returning migrating birds [49]. Indeed, Hyalomma immatures have also been found on bird species of both groups returning to or present in their breeding area [5-13,50-52], also in the Netherlands [15]. The Hyalomma ticks reported in this study were most likely introduced at the locations in early spring by migratory birds as engorged nymphs, and moulted to adult stage. The horses and persons on which the adult ticks were found had not (recently) been abroad. Also, in case of introduction of adult ticks with animal hosts (e.g. introduced via imported horses), more specimens found at one location would be expected [31, $33,46]$.

As shown by the results of the cumulative daily temperature analyses, the temperatures recorded between September and December of 2018 and 2019 do not correspond to the areas where $H$. marginatum has permanent populations. As suggested by Gray et al. (2009), these parameters (average cumulative temperature of $800{ }^{\circ} \mathrm{C}$ in places where the tick has permanent populations, and below $400{ }^{\circ} \mathrm{C}$ in sites not colonized) are related to local factors that affect the moulting of nymphs to adult stage before the onset of winter. These parameters are not related to (extreme) cold winter temperatures that prevent wintering adults from surviving into the next year, because unfed adults of Hyalomma are very capable of surviving even harsh winter conditions in continental climates, probably hidden deeply in the litter layer $[32,46]$. Therefore, temperatures in late summer and autumn are more critical for potential Hyalomma survival and establishment of permanent populations than temperatures in winter.

Results according to the Emelyanova et al. criteria [44] show that the early sightings (before August) of adult Hyalomma ticks in the Netherlands do not align with the suggested temperature accumulation. According to these criteria, introduced engorged nymphs in 2019 and 2020 could not moult to adults within this time period, suggesting that adult Hyalomma ticks that were sighted before August wintered at these locations. A period of at least 4 months would have been necessary in 2019 for engorged nymphs to moult into adults. Taking into consideration the probability of survival of the moulting ticks during such a 4-month period exposed to (environmental) factors such as predation, parasitism, fungal infections, drowning or desiccation [31, 53, 54], this period can be considered too long and the proposed parameters less appropriate. Applying the criterion proposed by Gale et al. [45], engorged nymphs that arrived at the end of March or in April could have moulted to adults in the first days of May in 2019 and 2020, matching the sightings of the first adults. The criterion used by Gale et al. [45] and accepted for the $H$. marginatum populations maintained in Spain (Estrada-Peña personal communication) is based on temperature as the main factor affecting the seasonal pattern of the H. marginatum tick (EstradaPeña et al. 2011) and is therefore used as the sole parameter for moulting. Other critical parts of the life cycle necessary for the establishment of permanent populations besides nymphal moulting and wintering of adults $[46,49,53]$, such as oviposition by the adult females and questing and moulting activity of all stages, are heavily dependent on (micro)climatic conditions as well [53]. This explains why in areas where climatic conditions are favourable for moulting from nymph to adult, this does not automatically lead to permanent populations of $\mathrm{Hya}$ lomma ticks.

Besides climatic factors, tick densities and dispersal are also important factors for possible establishment of Hyalomma [28, 53]. All sightings of Hyalomma ticks so far were singular, and no other Hyalomma ticks were reported by the citizens or detected by us in the vicinity of the reported adult Hyalomma tick. Also, no Hyalomma ticks were found in the horse screening part of this study. Although it is likely that more Hyalomma ticks are present than sighted, we hypothesize that these ticks are still too dispersed to find a mating partner (Allee effect $[55,56])$. With the current seemingly occasional introduction on migratory birds, the chance for adult females to encounter adult males for mating on the same mammalian host can be considered very low. However, we cannot conclude that this event is impossible or could not have already happened. To detect attached larvae or nymphs, active (more site-directed) monitoring on small mammals and resident birds would need to be implemented in early spring, at least in areas where Hyalomma has been sighted. Besides the above-mentioned factors, the availability and densities of suitable hosts are also important. Given that birds, rodents, lagomorphs, and wild and domestic ungulates are abundant in the Netherlands, this will probably not be the most limiting factor.

Taking the above-mentioned into account, we hypothesize that engorged nymphs arriving on migratory birds in spring are able to moult to adults under the current Dutch climatic conditions in spring and summer. $H$. marginatum is currently not able to establish permanent populations due to the climate. For $H$. rufipes, which is distributed in drier areas of Africa and prefers arid conditions [35], it seems even more unlikely that permanent populations will be established in the Netherlands, which 
is classified as $\mathrm{Cfb}$ (temperate oceanic) according to the Köppen-Geiger climate classification [57].

$\mathrm{CCHFv}$ was not detected in any of the tested ticks (13 adults and one nymph). False-negative results for $\mathrm{CCHFv}$ (a RNA virus), due to the time it took to arrive at the laboratory after discovery (average 1.9 days, range $0-4$ days) or issues of storage by citizens and transport, obviously cannot be ruled out. However, our findings are in accordance with other studies performed in western and northern countries which tested for CCHFv in Hyalomma ticks [11, 16-18, 20, 22, 23]. CCHFv-positive Hyalomma ticks can be found in ticks collected in regions in and around Europe that lie closer to CCHFv endemic regions $[8,9$, 58]. CCHFv also seems to have a focal geographic distribution range in regions where competent vector tick species are established [33]. Complex interactions between tick vector species, reservoir hosts, climate (change) and social changes leading to alterations in vegetation and use of landscape determine the enzootic cycle of CCHFv and human outbreaks [59]. Widespread occurrence of vectors and reservoirs does not necessarily lead to outbreaks of $\mathrm{CCHFv}$ in humans, and even though climate may favour competent tick populations, it is not directly linked to the presence of CCHFv [60]. This makes it difficult to predict the dynamics of CCHFv in areas where potential reservoirs are present, the competent vectors are occasionally introduced and climate is changing, as is the current situation in the Netherlands. CCHFv was recently found in Hyalomma ticks in Spain [61], and at a later stage evidence of circulation of the virus in wildlife was found in parts of Spain, including human cases $[62,63]$. The virus strain found in Spain belongs to a cluster of strains isolated in western Africa, and it was estimated that it was introduced in Spain around 50 years prior to the first human cases [64]. This finding shows that enzootic cycles can be present unnoticed for quite some time. Although other tick species are also involved in the epidemiology of CCHFv, H. marginatum is considered the principal vector in Europe [33, 65]. Because both transstadial and transovarial transmission of the virus in ticks is possible, Hyalomma ticks can also form a reservoir of CCHFv [53]. To estimate the risk of introduction of CCHFv via $\mathrm{Hya}$ lomma ticks imported by migratory birds, the dynamics between the virus, the tick and feeding on a non-viremic host need to be clarified. In summary, taking into account that (i) only a small percentage of larvae in endemic areas are infected via transovarial transmission $[45,60,66]$, (ii) viremic transmission of ticks via migratory birds [60, 67] and transmission of CCHFv via co-feeding on migratory birds seems unlikely [33], (iii) transstadial transmission is only successful in a little more than a third of the ticks and perhaps lower in ticks feeding on birds [66, 68], (iv) H. marginatum immatures are most likely dropped off only occasionally in northern and western European regions, and (v) no $\mathrm{CCHFv}$ has been found so far in Hyalomma ticks in northern and western European countries, the chance of human exposure to CCHFv via Hyalomma ticks in the Netherlands is currently considered very low.

The presence of the strictly intracellular bacterium Rickettsia, of which the species aeschlimannii was found in our study in one tick, is reported much more often in Hyalomma ticks [14, 17-19, 23, 51, 58, 69, 70]. The reason for this might be that Rickettsia spp. are considered heritable symbionts from invertebrates [71, 72].

The ticks tested negative for the parasites Babesia and Theileria. This is in accordance with other studies that tested Hyalomma ticks for Babesia and Theileria species in northern and western European countries [17, 18, 20]. Bovine tropical theileriosis ( $T$. annulata) is present only in the southern parts of Europe and to our knowledge has not been detected in north-western European countries, but equine piroplasmosis (B. caballi/T. equi) is occasionally diagnosed outside its endemic range [73]. In fact, a study revealed piroplasmosis in horses in the south-western part of the Netherlands in 2010. Not all horses had been abroad, suggesting autochthonous infections, most likely caused by Dermacentor reticulatus ticks [74, 75]. Because Theileria parasites are not transmitted transovarially, the risk of the introduction of Theileria with Hyalomma ticks seems negligibly low [32]. We also estimate the risk of introducing Babesia through Hyalomma ticks as very low, although it must be taken into account that this protozoan can be transmitted transovarially [76].

\section{Conclusion}

Hyalomma ticks are regularly introduced into areas outside their current living range, and our results show that alert citizens can detect the presence of a Hyalomma tick and report the sighting to the authorities. We hypothesize that as of summer 2019, citizens were more alert to Hyalomma ticks than in previous years. The awareness, caused by media reports of sightings, in combination with the intensive care (e.g. brushing) of horses could be the reasons that a relatively large number of ticks were reported in 2019 and 2020 compared to previous years, and that most Hyalomma ticks were found on horses. Under our current climatic conditions, introduced engorged nymphs are able to moult into adults, but the establishment of permanent Hyalomma populations is considered unlikely. We estimate the current probability of introduction of Hyalomma tick-borne pathogens in the Netherlands as very low, with the exception of $R$. aeschlimannii, of which there is existing risk, as demonstrated by our results, and to a lesser extent B. caballi. 
Abbreviations

CCHFv: Crimean-Congo haemorrhagic fever virus; CMV: Centre for Monitoring of Vectors; gltA: Citrate synthase gene; NVWA: Netherlands Food and Consumer Product Safety Authority; ompB: Outer membrane protein B gene; RIVM: National Institute for Public Health and the Environment; s.l.: Sensu lato; UPGMA: Unweighted pair group method with arithmetic mean.

\section{Supplementary Information}

The online version contains supplementary material available at https://doi. org/10.1186/s13071-021-04738-x.

Additional file 1: Table S1. Graphic image of all reports to the CMV, including Hyalomma (June 2019-December 2020). Table S2. Hyalomma sp. GenBank ${ }^{\circledR}$ accession numbers $(n=77)$ used for the cluster analysis.

\section{Acknowledgements}

We would like to thank everyone who reported suspicious Hyalomma ticks to the CMV for their cooperation. Also, we thank inspectors and other employees of the NVWA who contributed to the Hyalomma work.

\begin{abstract}
Authors' contributions
$\mathrm{MU}, \mathrm{AIJ}, \mathrm{AS}$ and FJ were involved in the collection and processing of the samples reported by citizens. FJ, AIJ and AS performed the morphological identification of the reports made by citizens. The cross-sectional horse study was designed by HS, RN, PO and CD and performed by CD. HS, RN and PO supervised CD (veterinary student). BvdV performed the cluster analysis, in consultation with MU, AIJ and HS. AIJ performed the climate analyses, in consultation with MU. HS supervised the pathogen detection work. MU and AlJ wrote the manuscript. All authors provided relevant input at different stages of manuscript preparation. All authors read and approved the final manuscript.
\end{abstract}

\section{Funding}

Not applicable.

\section{Availability of data and materials}

Hyalomma sequences generated in this study were submitted to NCBI GenBank ${ }^{\circledR}$ under accession numbers MT757612 to MT757622, and MW495246 to MW495248. The Rickettsia aeschlimannii sequence generated in this study was submitted to the NCBI GenBank ${ }^{\circledR}$ under accession number MW498244. Data supporting the conclusions of this article are included within the article and its additional file. A limited amount of DNA/RNA from samples is available upon reasonable request.

\section{Declarations}

Ethics approval and consent to participate

Not applicable.

\section{Consent for publication}

Not applicable.

\section{Competing interests}

The authors declare that they have no competing interests.

\footnotetext{
Author details

${ }^{1}$ Centre for Monitoring of Vectors (CMV), National Reference Laboratory, Netherlands Food and Consumer Product Safety Authority (NVWA), Wageningen, the Netherlands. ${ }^{2}$ National Plant Protection Organization (NPPO-NL), National Reference Laboratory, Netherlands Food and Consumer Product Safety Authority (NVWA), Wageningen, the Netherlands. ${ }^{3}$ Institute for Risk Assessment Sciences (IRAS), Faculty of Veterinary Medicine, Utrecht University, Utrecht, the Netherlands. ${ }^{4}$ Department of Infectious Diseases and Immunology, Faculty of Veterinary Medicine, Utrecht University, Utrecht, the Netherlands. ${ }^{5}$ Centre for Infectious Disease Control (Clb), National Institute for Public Health and the Environment (RIVM), Bilthoven, the Netherlands.
}

Received: 22 February 2021 Accepted: 21 April 2021

Published online: 07 May 2021

\section{References}

1. Gargili A, Thangamani S, Bente D. Influence of laboratory animal hosts on the life cycle of Hyalomma marginatum and implications for an in vivo transmission model for Crimean-Congo hemorrhagic fever virus. Front Cell Infect Microbiol. 2013;3:39.

2. Vial L, Stachurski F, Leblond A, Huber K, Vourc'h G, René-Martellet M, et al. Strong evidence for the presence of the tick Hyalomma marginatum Koch, 1844 in southern continental France. Ticks Tick Borne Dis. 2016;7:1162-7.

3. ECDC. Hyalomma marginatum — current known distribution: May 2020 ECDC. https://www.ecdc.europa.eu/en/publications-data/hyalommamarginatum-current-known-distribution-may-2020

4. Hoogstraal H, Kaiser MN, Traylor MA, Gaber S, Guindy E. Ticks (Ixodoidea) on birds migrating from Africa to Europe and Asia. Bull World Health Organ. 1961;24:197-212.

5. Capek M, Literak I, Kocianova E, Sychra O, Najer T, Trnka A, et al. Ticks of the Hyalomma marginatum complex transported by migratory birds into Central Europe. Ticks Tick Borne Dis. 2014;5:489-93.

6. Poupon M, Lommano E, Humair PF, Douet $V$, Rais $O$, Schaad M, et al. Prevalence of Borrelia burgdorferi sensu lato in ticks collected from migratory birds in Switzerland. Appl Environ Microbiol. 2006;72:976-9.

7. Toma L, Mancini F, Di Luca M, Cecere JG, Bianchi R, Khoury C, et al. Detection of microbial agents in ticks collected from migratory birds in central Italy. Vector Borne Zoonot Dis. 2014;14:199-205.

8. Mancuso E, Toma L, Polci A, d'Alessio SG, Di Luca M, Orsini M, et al. Crimean-Congo hemorrhagic fever virus genome in tick from migratory bird. Italy Emerg Infect Dis. 2019;25:1418-20.

9. England ME, Phipps P, Medlock JM, Atkinson PM, Atkinson B, Hewson R, et al. Hyalomma ticks on northward migrating birds in southern Spain: Implications for the risk of entry of Crimean-Congo haemorrhagic fever virus to Great Britain. J Vector Ecol. 2016;41:128-34.

10. Sparagano O, George D, Giangaspero A, Špitalská E. Arthropods and associated arthropod-borne diseases transmitted by migrating birds. The case of ticks and tick-borne pathogens. Vet Par. 2015;213:61-6.

11. Jameson LJ, Morgan PJ, Medlock JM, Watola G, Vaux AG. Importation of Hyalomma marginatum, vector of Crimean-Congo haemorrhagic fever virus, into the United Kingdom by migratory birds. Ticks Tick Borne Dis. 2012;3:95-9.

12. Labbe Sandelin L, Tolf C, Larsson S, Wilhelmsson P, Salaneck E, Jaenson TG, et al. Candidatus Neoehrlichia mikurensis in ticks from migrating birds in Sweden. PLOS ONE. 2015;107:e0133250.

13. Hasle G, Bjune G, Edvardsen E, Jakobsen C, Linnehol B, Roer JE, et al. Transport of ticks by migratory passerine birds to Norway. J Parasitol. 2009;95:1342-51.

14. Battisti E, Urach K, Hodžić A, Fusani L, Hufnagl P, Felsberger G, et al. Zoonotic pathogens in ticks from migratory birds, Italy. Emerg Infect Dis. 2020;26:2986-8.

15. Heylen D, Fonville M, Docters van Leeuwen A, Stroo A, Duisterwinkel M, van Wieren S, et al. Pathogen communities of songbird-derived ticks in Europe's low countries. Parasites Vectors. 2017. https://doi.org/10.1186/ s13071-017-2423-y.

16. Chitimia-Dobler L, Nava S, Bestehorn M, Dobler G, Wolfel S. First detection of Hyalomma rufipes in Germany. Ticks Tick Borne Dis. 2016;7:1135-8.

17. Chitimia-Dobler L, Schaper S, Riess R, Bitterwolf K, Frangoulidis D, Bestehorn M, et al. Imported Hyalomma ticks in Germany in 2018. Parasites Vectors. 2019;12:134.

18. Hansford KM, Carter D, Gillingham EL, Hernandez-Triana LM, Chamberlain J, Cull B, et al. Hyalomma rufipes on an untraveled horse: Is this the first evidence of Hyalomma nymphs successfully moulting in the United Kingdom? Ticks Tick Borne Dis. 2019;10(3):704-8.

19. Rumer L, Graser E, Hillebrand T, Talaska T, Dautel H, Mediannikov O, et al. Rickettsia aeschlimannii in Hyalomma marginatum ticks, Germany. Emerg Infect Dis. 2011;17:325-6.

20. Grandi G, Chitimia-Dobler L, Choklikitumnuey P, Strube C, Springer A, Albihn A, et al. First records of adult Hyalomma marginatum and $H$. rufipes ticks (Acari: Ixodidae) in Sweden. Ticks Tick Borne Dis. 2020;11(3):101403. 
21. McGinley L, Hansford KM, Cull B, Gillingham EL, Carter DP, Chamberlain JF, et al. First report of human exposure to Hyalomma marginatum in England: further evidence of a Hyalomma moulting event in north-western Europe? Ticks Tick Borne Dis. 2020;12(1):101541.

22. Oehme R, Bestehorn M, Wölfel S, Chitimia-Dobler L. Hyalomma marginatum in Tübingen, Germany. SystAppl Acarol. 2017;22:1-6.

23. Duscher GG, Hodžić A, Hufnagl P, Wille-Piazzai W, Schötta AM, Markowicz MA, et al. Adult Hyalomma marginatum tick positive for Rickettsia aeschlimannii in Austria, October 2018. Euro Surveill. 2018;23:1800595.

24. Nijhof AM, Bodaan C, Postigo M, Nieuwenhuijs H, Opsteegh M, Franssen $L$, et al. Ticks and associated pathogens collected from domestic animals in the Netherlands. Vector Borne Zoonotic Dis. 2007;7:585-95.

25. Butler CM, Sloet van Oldruitenborgh-Oosterbaan M, Werners AH, Stout TAE, Jongejan F, Houwers D. Classification of ticks collected from horses in the Netherlands in2008-2009 and identification of the (zoonotic) agents they contain. Pferdeheilkunde 2016;32(4):329

26. Graveland H, Roest $H$, Stenvers O, Valkenburgh S, Friesema I, van der Giessen J, et al: Staat van Zoönosen 2012. RIVM The Netherlands 2013: 44.

27. Estrada-Peña A, Pfäffle M, Baneth G, Kleinerman G, Petney TN. Ixodoidea of the Western Palaearctic: a review of available literature for identification of species. Ticks Tick Borne Dis. 2017;8:512-25.

28. Spengler JR, Estrada-Peña A. Host preferences support the prominent role of Hyalomma ticks in the ecology of Crimean-Congo hemorrhagic fever. PLOS Negl Trop Dis. 2018;12:e0006248.

29. Estrada-Peña A, de la Fuente J. The ecology of ticks and epidemiology of tick-borne viral diseases. Antiviral Res. 2014;108:104-28.

30. Hoogstraal H. The epidemiology of tick-borne Crimean-Congo hemorrhagic fever in Asia, Europe, and Africa. J Med Entomol. 1979;15:307-417.

31. Valcárcel F, González J, González MG, Sánchez M, Tercero JM, Elhachimi $L$, et al. Comparative ecology of Hyalomma lusitanicum and Hyalomma marginatum Koch, 1844 (Acarina: Ixodidae). Insects. 2020;11(5):303.

32. Bakheit MA, Latif AA, Vatansever Z, Seitzer U, Ahmed J. The huge risks due to hyalomma ticks. In: Mehlhorn $\mathrm{H}$, editor. Arthropods as vectors of emerging diseases parasitol res monographs, vol. 3. Berlin, Heidelberg: Springer; 2012.

33. EFSA. Scientific opinion on the role of tick vectors in the epidemiology of Crimean-Congo hemorrhagic fever and African swine fever in Eurasia, EFSA Panel on Animal Health and Welfare (AHAW). EFSA J. 2010;8:156.

34. Parola P, Paddock CD, Socolovschi C, Labruna MB, Mediannikov O, Kernif T, et al. Update on tick-borne rickettsioses around the world: aA geographic approach. Clin Microbiol Rev. 2013;26:657-702.

35. Estrada-Peña A, Mihalca AD, Petney TN. Ticks of Europe and North America. Springer International Publishing; 2017.

36. Walker AR, Bouattour A, Camicas JL, Estrada-Peña A, Horak IG, Latif AA, et al. Ticks of domestic animals in Africa: a guide to identification of species. Edinburgh Scotland, U.K.: Bioscience Reports; 2014.

37. Hebert PD, Cywinska A, Ball SL, deWaard JR. Biological identifications through DNA barcodes. Proc Biol Sci. 2003;270:313-21.

38. EPPO/OEPP. PM 7/129 (1) DNA barcoding as an identification tool for a number of regulated pests. EPPO Bull. 2016;46:501-37

39. Katoh K, Misawa K, Kuma K, Miyata T. MAFFT: a novel method for rapid multiple sequence alignment based on fast Fourier transform. Nucleic Acids Res. 2002;30:3059-66.

40. Wolfel R, Paweska JT, Petersen N, Grobbelaar AA, Leman PA, Hewson R, et al. Virus detection and monitoring of viral load in Crimean-Congo hemorrhagic fever virus patients. Emerg Infect Dis. 2007;13:1097-100.

41. Wielinga PR, Fonville M, Sprong H, Gaasenbeek C, Borgsteede F, van der Giessen JW. Persistent detection of Babesia EU1 and Babesia microti in Ixodes ricinus in the Netherlands during a 5-year surveillance: 2003-2007. Vector Borne Zoonotic Dis. 2009;9:119-22.

42. Stenos J, Graves SR, Unsworth NB. A highly sensitive and specific realtime PCR assay for the detection of spotted fever and typhus group Rickettsiae. Am J Trop Med Hyg. 2005;73:1083-5.

43. Roux V, Raoult D. Phylogenetic analysis of members of the genus Rickettsia using the gene encoding the outer-membrane protein $\mathrm{rOmpB}$ (ompB). Int J Syst Evol. 2000;50:1449-55.

44. Emelyanova N. Seasonal changes and host adaptability of ticks of the species Hyalomma marginatum in the Stavropol territory. Zurnal Mikrobiologii Epidemiologii I Immunobiologii. 2005;4:115-8.
45. Gale P, Stephenson B, Brouwer A, Martinez M, de la Torre A, Bosch J, et al. Impact of climate change on risk of incursion of Crimean-Congo haemorrhagic fever virus in livestock in Europe through migratory birds. J Appl Microbiol. 2012;112:246-57.

46. Gray JS, Dautel H, Estrada-Peña A, Kahl O, Lindgren E. Effects of climate change on ticks and tick-borne diseases in Europe. Interdiscip Perspect Infect Dis. 2009:2009:1-12.

47. Höhenheim U. Tropische Zecken: Neu eingewanderte Art überwintert erstmals in Deutschland. 2019. https://www.uni-hohenheim.de/press emitteilung?tx_ttnews\%5Btt_news\%5D $=43734 \&$ cHash $=5 \mathrm{fd} 3 \mathrm{c0e}$ da 33d842f4ee127beaf7b078

48. Rees DJ, Dioli M, Kirkendall LR. Molecules and morphology: evidence for cryptic hybridization in African Hyalomma (Acari: Ixodidae). Mol Phylogenet Evol. 2003;27:131-42.

49. Bosch J, Muñoz MJ, Martínez M, de la Torre A, Estrada-Peña A. Vectorborne pathogen spread through ticks on migratory birds: a probabilistic spatial risk model for south-western Europe. Transbound Emerg Dis. 2013:60:403-15.

50. Wallmenius $K$, Barboutis $C$, Fransson T, Jaenson TG, Lindgren PE, Nystrom F, et al. Spotted fever Rickettsia species in Hyalomma and Ixodes ticks infesting migratory birds in the European Mediterranean area. Parasites Vectors. 2014;7:318.

51. Socolovschi C, Reynaud P, Kernif T, Raoult D, Parola P. Rickettsiae of spotted fever group, Borrelia valaisiana, and Coxiella burnetii in ticks on passerine birds and mammals from the Camargue in the south of France. Ticks Tick Borne Dis. 2012;5-6:355-60.

52. Hubálek Z, Sedláček P, Estrada-Peña A, Vojtíšek J, Rudolf I. First record of Hyalomma rufipes in the Czech Republic, with a review of relevant cases in other parts of Europe. Ticks Tick Borne Dis. 2020;11:101421.

53. Estrada-Peña A, Martinez Aviles M, Munoz Reoyo MJ. A population model to describe the distribution and seasonal dynamics of the tick Hyalomma marginatum in the Mediterranean Basin. Transbound Emerg Dis. 2011;58:213-23.

54. Ogden NH, Mechai S, Margos G. Changing geographic ranges of ticks and tick-borne pathogens: drivers, mechanisms and consequences for pathogen diversity. Front Cell Infect Microbiol. 2013;3:46.

55. Lampert A, Liebhold AM. Combining multiple tactics over time for cost-effective eradication of invading insect populations. Ecol Lett. 2021;24:279-87.

56. Tobin $P C$, Berec $L$, Liebhold AM. Exploiting Allee effects for managing biological invasions. Ecol Lett. 2011;14(6):615-24.

57. MacLeod A, Korycinska A. Detailing Köppen-Geiger climate zones at subnational to continental scale: a resource for pest risk analysis. EPPO Bull. 2019;49:73-82

58. Azagi T, Klement E, Perlman G, Lustig Y, Mumcuoglu KY, Apanaskevich DA et al. Francisella-like Endosymbionts and Rickettsia species in local and imported Hyalomma ticks. Appl Environ Microbiol. 2017. https://doi.org/ 10.1128/AEM.01302-17

59. Vescio FM, Busani L, Mughini-Gras L, Khoury C, Avellis L, Taseva E, et al. Environmental correlates of Crimean-Congo haemorrhagic fever incidence in Bulgaria. BMC Public Health. 2012;12:1116.

60. Estrada-Peña A, Jameson L, Medlock J, Vatansever Z, Tishkova F. Unraveling the ecological complexities of tick-associated Crimean-Congo hemorrhagic fever virus transmission: a gap analysis for the western Palearctic. Vector Borne Zoonotic Dis. 2012;12:743-52.

61. Estrada-Peña A, Palomar AM, Santibanez P, Sanchez N, Habela MA, Portillo $A$, et al. Crimean-Congo hemorrhagic fever virus in ticks, Southwestern Europe, 2010. Emerg Infect Dis. 2012;18:179-80.

62. Negredo A, de la Calle-Prieto F, Palencia-Herrejon E, Mora-Rillo M, AstrayMochales J, Sanchez-Seco MP, et al. Autochthonous Crimean-Congo hemorrhagic fever in Spain. N Engl J Med. 2017;377:154-61.

63. Monsalve Arteaga L, Muñoz Bellido JL, Vieira Lista MC, Vicente Santiago $M B$, Fernández Soto P, Bas I, et al. Crimean-Congo haemorrhagic fever (CCHF) virus-specific antibody detection in blood donors, Castile-León, Spain, summer 2017and 2018. Euro Surveill. 2020. https://doi.org/10. 2807/1560-7917.ES.2020.25.10.1900507.

64. Cajimat MNB, Rodriguez SE, Schuster IUE, Swetnam DM, Ksiazek TG, Habela MA, et al. Genomic Characterization of Crimean-Congo Hemorrhagic Fever Virus in Hyalomma Tick from Spain, 2014. Vector Borne Zoonotic Dis (Larchmont, NY). 2017;17(10):714-9. https://doi.org/10.1089/vbz.2017. 2190 
65. Monsalve-Arteaga L, Alonso-Sardón M, Muñoz Bellido JL, Vicente Santiago MB, Vieira Lista MC, López Abán J, et al. Seroprevalence of Crimean-Congo hemorrhagic fever in humans in the World Health Organization European region: a systematic review. PLoS Negl Trop Dis. 2020;14(3):e0008094. https://doi.org/10.1371/journal.pntd.0008094.

66. Gargili A, Estrada-Peña A, Spengler JR, Lukashev A, Nuttall PA, Bente DA. The role of ticks in the maintenance and transmission of Crimean-Congo hemorrhagic fever virus: a review of published field and laboratory studies. Antiviral Res. 2017:144:93-119.

67. Hawman DW, Feldmann H. Recent advances in understanding CrimeanCongo hemorrhagic fever virus. F1000Research. 2018;7:1715.

68. Zeller HG, Cornet JP, Camicas JL. Experimental transmission of CrimeanCongo hemorrhagic fever virus by west African wild ground-feeding birds to Hyalomma marginatum rufipes ticks. Am J Trop Med Hyg. 1994;50:676-81.

69. Palomar AM, Portillo A, Mazuelas D, Roncero L, Arizaga J, Crespo A, et al. Molecular analysis of Crimean-Congo hemorrhagic fever virus and Rickettsia in Hyalomma marginatum ticks removed from patients (Spain) and birds (Spain and Morocco), 2009-2015. Ticks Tick Borne Dis. 2016;7:983-7.

70. Spiegelaar $\mathrm{N}$. The role of birds in disseminating ticks and tick-borne diseases of veterinary and medical importance. Thesis Utrecht University, The Netherlands; 2015

71. Parola P, Paddock CD, Raoult D. Tick-borne rickettsioses around the world: emerging diseases challenging old concepts. Clin Microbiol Rev. 2005;18:719-56

72. Alberdi MP, Dalby MJ, Rodriguez-Andres J, Fazakerley JK, Kohl A, Bell-Sakyi $L$. Detection and identification of putative bacterial endosymbionts and endogenous viruses in tick cell lines. Ticks Tick Borne Dis. 2012;3:137-46.

73. OIE: WAHIS Interface World Animal Health Disease Information.
74. Butler CM, Sloet van Oldruitenborgh-Oosterbaan MM, Stout TAE, van der Kolk JH, van den Wollenberg L, Nielen M, et al. Prevalence of the causative agents of equine piroplasmosis in the South West of The Netherlands and the identification of two autochthonous clinical Theileria equi infections. Vet J. 2012;193(2):381-5

75. Jongejan F, Ringenier M, Putting M, Berger L, Burgers S, Kortekaas R, et al. Novel foci of Dermacentor reticulatus ticks infected with Babesia canis and Babesia caballi in the Netherlands and in Belgium. Parasit Vectors. 2015;8:232.

76. Onyiche TE, Suganuma K, Igarashi I, Yokoyama N, Xuan X, Thekisoe O. A review on equine piroplasmosis: epidemiology, vector ecology, risk factors, host immunity, diagnosis and control. Int J Envir Res Public Health. 2019;16(10):1736.

\section{Publisher's Note}

Springer Nature remains neutral with regard to jurisdictional claims in published maps and institutional affiliations.
Ready to submit your research? Choose BMC and benefit from:

- fast, convenient online submission

- thorough peer review by experienced researchers in your field

- rapid publication on acceptance

- support for research data, including large and complex data types

- gold Open Access which fosters wider collaboration and increased citations

- maximum visibility for your research: over $100 \mathrm{M}$ website views per year

At BMC, research is always in progress.

Learn more biomedcentral.com/submissions 